University of Nebraska - Lincoln

DigitalCommons@University of Nebraska - Lincoln

Stephen Ducharme Publications

Research Papers in Physics and Astronomy

7-2009

\title{
Polarization switching kinetics of ferroelectric nanomesas of vinylidene fluoride-trifluoroethylene copolymer
}

\author{
R. V. Gaynutdinov \\ Institute of Crystallography, Russian Academy of Science, Moscow, rgaynutdinov@gmail.com
}

O. A. Lysova

Institute of Crystallography, Russian Academy of Science, Moscow

S. G. Yudin

Institute of Crystallography, Russian Academy of Science, Moscow

A. L. Tolstikhina

Institute of Crystallography, Russian Academy of Science, Moscow

A. L. Kholkin

University of Aviero, Portugal

See next page for additional authors

Follow this and additional works at: https://digitalcommons.unl.edu/physicsducharme

Part of the Condensed Matter Physics Commons, and the Polymer and Organic Materials Commons

Gaynutdinov, R. V.; Lysova, O. A.; Yudin, S. G.; Tolstikhina, A. L.; Kholkin, A. L.; Fridkin, V. M.; and Ducharme, Stephen, "Polarization switching kinetics of ferroelectric nanomesas of vinylidene fluoridetrifluoroethylene copolymer" (2009). Stephen Ducharme Publications. 53.

https://digitalcommons.unl.edu/physicsducharme/53

This Article is brought to you for free and open access by the Research Papers in Physics and Astronomy at DigitalCommons@University of Nebraska - Lincoln. It has been accepted for inclusion in Stephen Ducharme Publications by an authorized administrator of DigitalCommons@University of Nebraska - Lincoln. 


\section{Authors}

R. V. Gaynutdinov, O. A. Lysova, S. G. Yudin, A. L. Tolstikhina, A. L. Kholkin, V. M. Fridkin, and Stephen Ducharme 


\title{
Polarization switching kinetics of ferroelectric nanomesas of vinylidene fluoride-trifluoroethylene copolymer
}

\author{
R. V. Gaynutdinov, ${ }^{1}$ O. A. Lysova, ${ }^{1}$ S. G. Yudin, ${ }^{1}$ A. L. Tolstikhina, ${ }^{1}$ A. L. Kholkin, ${ }^{2}$ \\ V. M. Fridkin, ${ }^{1, a)}$ and Stephen Ducharme ${ }^{3, b)}$ \\ ${ }^{1}$ Institute of Crystallography of Russian Academy of Sciences, Moscow 119333, Russia \\ ${ }^{2}$ Department of Ceramics, University of Aveiro, Aveiro 3810-193, Portugal \\ ${ }^{3}$ Department of Physics and Astronomy, Nebraska Center for Materials and Nanoscience, \\ University of Nebraska, Lincoln, Nebraska 68588-0111, USA
}

(Received 24 February 2009; accepted 18 June 2009; published online 14 July 2009)

\begin{abstract}
The polarization switching kinetics of ferroelectric polymer nanomesas was investigated using piezoresponse force microscopy. The nanomesas were made by self-organization from LangmuirBlodgett films of a 70\% vinylidene fluoride and 30\% trifluoroethylene copolymer. The polarization switching time exhibits an exponential dependence on reciprocal voltage that is consistent with nucleation-type switching dynamics. (C) 2009 American Institute of Physics.

[DOI: $10.1063 / 1.3176213$ ]
\end{abstract}

The speed of polarization reversal, switching, is of critical importance to the performance of ferroelectric memory technology. It is therefore essential to be able to understand and control switching dynamics in thin films and nanostructures as memories are pushed to ever higher densities. In crystals thicker than $50 \mu \mathrm{m}$, the switching time generally depends on the electric field, ${ }^{1}$ but not explicitly on crystal dimensions, and this is understood in terms of nucleation and domain-growth models. ${ }^{2,3}$ In thinner crystals, switching becomes progressively slower for a given electric field, ${ }^{1,4,5}$ indicating a qualitative change. There have been relatively few studies of polarization dynamics in ferroelectric nanostructures, for example, with nanowires, ${ }^{6,7}$ nanotubes, ${ }^{8}$ and nanodots. ${ }^{9,10}$

The importance of nanoscale structure and morphology is underlined by qualitative changes in the behavior of switching in ferroelectric polymer thin films depending on both thickness and sample preparation conditions. ${ }^{4,11-15}$ Prior studies have not been adequate to distinguish the effects of thickness and morphology because they were made on polycrystalline samples of essentially two types. Most studies have been performed on films made by solution spin coating, which produces disordered granular films consisting of nanocrystals approximately $200 \mathrm{~nm}$ long and $50 \mathrm{~nm}$ in diameter, ${ }^{16}$ where the polymer chains fold back and forth across the short dimensions. ${ }^{17}$ Samples made by Langmuir-Blodgett (LB) deposition, on the other hand, consist of a polycrystalline mosaic where the polymer chains are aligned parallel to the film plane ${ }^{18,19}$ in crystals of irregular shape and typical lateral size of $30 \mathrm{~nm}$ to $50 \mathrm{~nm} .{ }^{20}$ Studies of switching dynamics in the LB films have shown both nucleation-limited ${ }^{21,22}$ and nucleation-free (intrinsic) ${ }^{23,24}$ behavior. To better understand the effects of nanoscale morphology, we have studied switching dynamics at the nanoscale in polycrystalline films ${ }^{25}$ and nanostructures. ${ }^{26}$ The purpose of this paper is to report an investigation of the kinetics of switching of individual ferroelectric polymer nanomesas using piezoresponse force microscopy (PFM).

\footnotetext{
${ }^{a)}$ Electronic mail: fridkin @ns.crys.ras.ru.

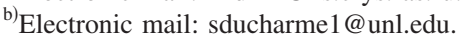

The nanomesas were fabricated from a ferroelectric copolymer by Langmuir-Blodgett deposition of a copolymer consisting of $70 \%$ vinylidene fluoride and $30 \%$ trifluoroethylene. ${ }^{27}$ Deposition was accomplished by dispersing a $1.3 \%$ by weight solution of the copolymer in dimethyl sulfoxide on the surface of ultrapure water at room temperature and compressed slowly to a pressure of $3 \mathrm{mN} / \mathrm{m}^{2}$. One monolayer was transferred to a silicon substrate coated with a 50-nm-thick aluminum film. To make the nanomesas, the sample was then heated to $125^{\circ} \mathrm{C}$ for $3 \mathrm{~h}$ and cooled to room temperature at a rate of $1{ }^{\circ} \mathrm{C}$ per min. The LB deposition and nanomesa formation methods are described in more detail elsewhere..$^{27,28}$

Measurements were carried out with a scanning probe microscope (model SOLVER P47 from NT-MDT, Moscow) operating in contact mode for imaging both topography (atomic force microscopy) and piezoresponse (PFM). The silicon cantilevers (model CSC38 from MicroMash, Estonia) had a lever force constant of approximately $0.05 \mathrm{~N} / \mathrm{m}$, a resonant frequency of $21 \mathrm{kHz}$, and tip radius of approximately $10 \mathrm{~nm}$. For the PFM measurements a CSC38 tip was coated with Ti/Pt conductive coating and had an estimated radius of $40 \mathrm{~nm}$ and an estimated imaging resolution of $60 \mathrm{~nm}$. The piezoresponse was obtained by applying an excitation voltage of amplitude $0.5 \mathrm{~V}$ and frequency $200 \mathrm{kHz}$ to the tip and recording the amplitude and phase of the resulting tip deflection signal from the cantilever position detector with a lock-in amplifier. The piezoresponse signal is enhanced, because the bias voltage frequency was just above the piezoresponse resonance frequency, which was between 180 and $190 \mathrm{kHz}$. The PFM images consist of $x-y$ maps of the composite PFM signal, which is equal to the PFM amplitude times the cosine of the PFM phase. The measurements were carried out in air in a class 10000 clean room maintained at temperature $26 \pm 0.05{ }^{\circ} \mathrm{C}$ and relative humidity $40 \pm 1 \%$. The sample temperature was held at $27{ }^{\circ} \mathrm{C}$.

The self-assembly led to the creation of nanomesas of ferroelectric copolymer approximately $20-30 \mathrm{~nm}$ thick and 100-200 nm in diameter, with somewhat irregular shapes [Fig. 1(a)]. The PFM image of the same region [Fig. 1(b)] shows that the nanomesas are polarized even before applying 
(a)

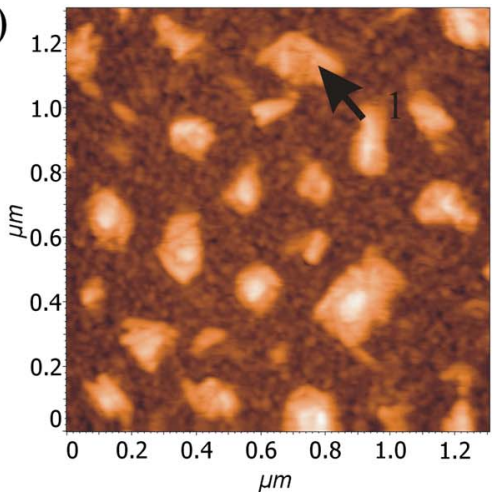

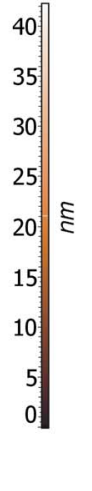

(b)

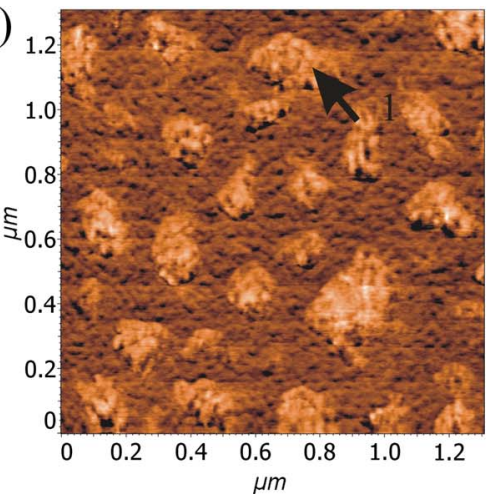

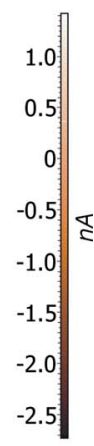

FIG. 1. (Color online) Images of nanomesas by (a) AFM topography; and (b) piezoresponse.

a bias voltage to the tip. For the switching studies, we chose the nanomesa indicated by arrow 1 in Fig. 1, where the thickness is $30 \mathrm{~nm}$. The sample polarization was altered by applying a constant bias voltage to the tip as it was scanned continuously across the sample. Figure 2 shows the PFM image, which is obtained from the piezoresponse signal (the amplitude times cosine of the phase), of nanomesa 1 and its neighbors in four states: (a) initially; (b) after applying a bias voltage of $-10 \mathrm{~V}$; (c) after applying a bias voltage of $V=+10 \mathrm{~V}$; (d) after again applying a bias voltage of $-10 \mathrm{~V}$. The comparison of Figs. 2(a)-2(d) shows that reversing the sign of the poling voltage also reversed, or switched, the sign of the piezoelectric response. These images show that the nanomesas could be switched repeatedly between opposing polarization states. Structures within the PFM images may indicate the presence of multiple crystals, or multiple domains, or both. The hysteresis loop was recorded by the pulse-measure method, ${ }^{29}$ which consists of applying a sequence of $20 \mathrm{~ms}$ voltage pulses at one location, starting at 0
$\mathrm{V}$, increasing in steps to $+10 \mathrm{~V}$, then to $-10 \mathrm{~V}$, and again to $+10 \mathrm{~V}$. Each bias pulse was followed by a measurement of the piezoresponse at zero bias. Figure 3 shows the resulting local hysteresis loop from nanomesa 1 . It exhibits clear saturation and a coercive voltage $V_{c}=1.8 \pm 0.1 \mathrm{~V}$ (uncertainty due to interpolation between data points), defined as the half width of the hysteresis loop. The hysteresis loop was shifted horizontally by $+1.6 \mathrm{~V}$, which is probably due in part to the asymmetry of the contacts. The observed vertical shift in the loop could be due to the polarization offset that is frequently observed in the piezoelectric measurements of ferroelectric thin films or due to nonswitchable surface dipoles. ${ }^{30}$

The switching kinetics were studied by a series of nanomesa switching measurements, ${ }^{24,25}$ where the crystal was first poled by scanning the tip with a saturating bias of $+10 \mathrm{~V}$ and imaged at zero voltage. Then a single negative voltage pulse of specified amplitude and duration was applied at one location and the resulting piezoresponse was recorded at zero voltage. The switching time $\tau$ for a given (a)
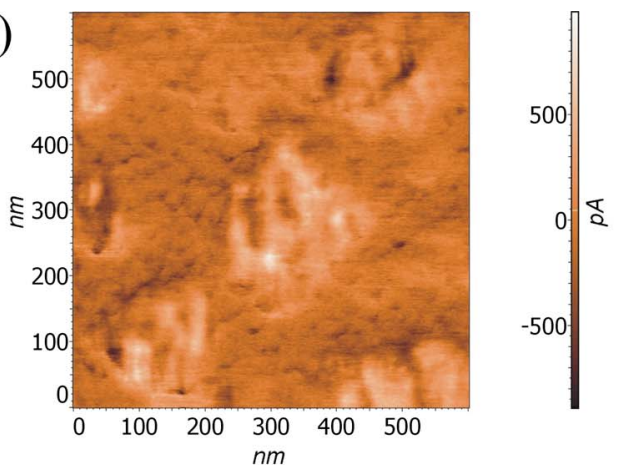

(c)
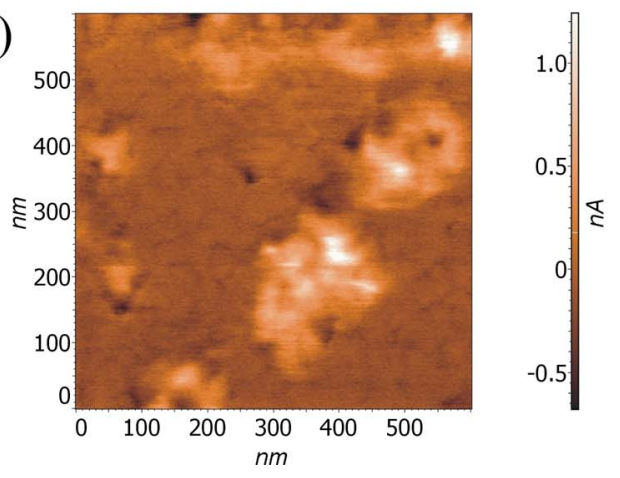

(b)
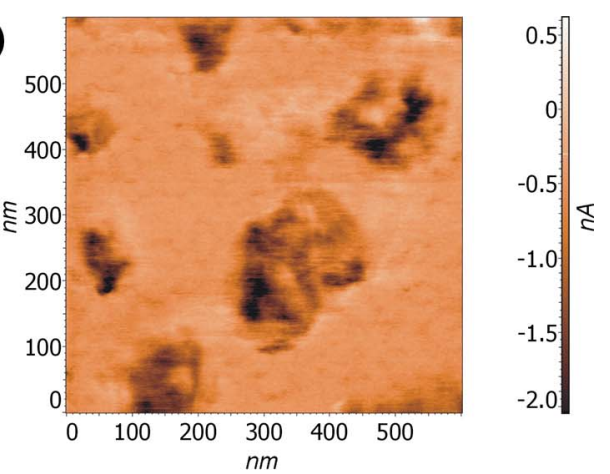

(d)

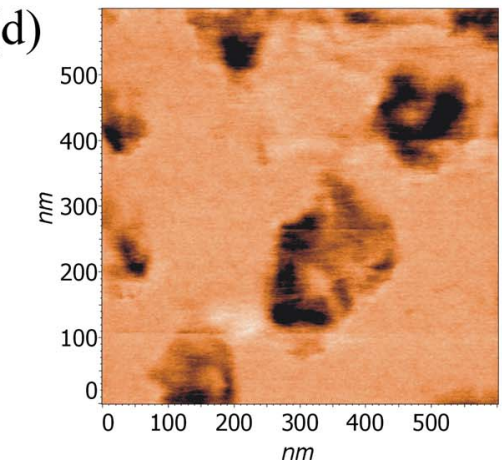

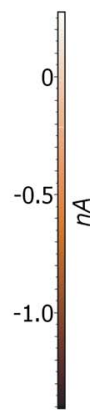

FIG. 2. (Color online) Piezoresponse images of the nanomesa indicated by the arrow 1 in Fig. 1(a) at the following stages: (a) initial phase image; (b) after applying a bias voltage of $-10 \mathrm{~V}$; (c) after applying a bias voltage of $V=+10 \mathrm{~V}$; (d) after again applying a bias voltage of $-10 \mathrm{~V}$. 


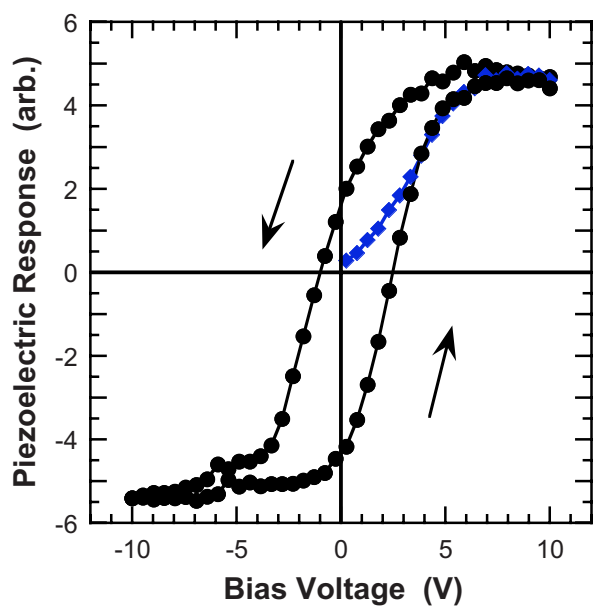

FIG. 3. (Color online) Piezoresponse hysteresis loop of the nanomesa indicated by the arrow 1 in Fig. 1.

pulse amplitude was defined as the value of the pulse duration for which the resulting piezoresponse crossed zero. This procedure was repeated for a range of switching pulse amplitudes and the results are shown in Fig. 4. The dependence of switching time $\tau$ on switching voltage $V$ is a useful indicator of the dominant switching mechanism. The data in Fig. 4 follow an exponential dependence of the form ${ }^{1}$

$$
1 / \tau=\exp \left(-a V_{C} / V\right)
$$

where $V_{C}=1.8 \pm 0.1 \mathrm{~V}$ is the coercive voltage from the hysteresis loop shown in Fig. 3(a) and $a=23 \pm 2$ is a constant. This dependence is characteristic of a switching process that proceeds by nucleation and domain-wall motion, which is an activated process. One may calculate an activation field $E_{a}$ $=a V_{C} / d$, where $d$ is the thickness, but with the AFM tip functioning as one electrode, the electric field in the sample is far from uniform. Keeping in mind this limitation, we calculate the activation field $E_{a}=1.4 \mathrm{GV} / \mathrm{m}$ (for $d=30 \mathrm{~nm}$ ), a little larger than the value $1 \mathrm{GV} / \mathrm{m}$ obtained with thin-film capacitors of a similar 73:27 composition copolymer. ${ }^{14}$

In summary, the observed dynamics of switching for an individual ferroelectric polymer nanomesa is consistent with a nucleation-limited process, as was found with arrays of similar nanomesas ${ }^{26}$ and with a 500 -nm-diameter spot in a continuous LB film. The nucleation-type switching behavior is commonly observed with ferroelectric polymer films made

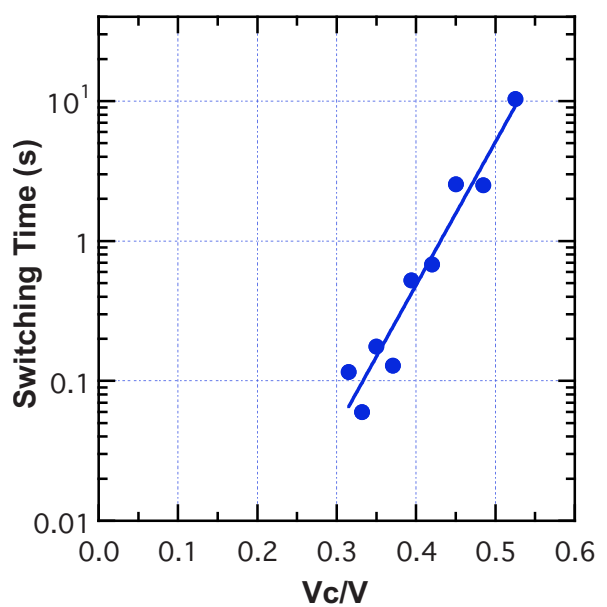

FIG. 4. (Color online) Graph of the switching rate (reciprocal switching time) vs $V_{c} / V$ for the nanomesa indicated by arrow 1 in Fig. 1. by solvent spinning, $4,11-15$ and with LB films made under certain conditions. ${ }^{21,22,24}$ This is in contrast to the behavior of the thinnest LB copolymer film capacitors, which exhibit intrinsic switching dynamics not controlled by nucleation or domains. ${ }^{23,24}$ Further study of local switching kinetics in ferroelectric thin films and nanostructures, especially including the dependence on temperature, is necessary if we are to understand the dominant mechanism and control it.

The work in Moscow was supported the European INTAS program, Grant No. 1000008-8091, and by the Russian Foundation for Basic Research (Grant Nos. 05-0216871 and 09-02-00096). The work in Lincoln was supported by the National Science Foundation (Grant No. ECS-0600130) and the Nebraska Research Initiative.

${ }^{1}$ W. J. Merz, J. Appl. Phys. 27, 938 (1956).

${ }^{2}$ E. Fatuzzo, Phys. Rev. 127, 1999 (1962).

${ }^{3}$ Y. Ishibashi, Jpn. J. Appl. Phys., Part 1 31, 2822 (1992).

${ }^{4}$ K. Kimura and H. Ohigashi, Jpn. J. Appl. Phys., Part 1 25, 383 (1986).

${ }^{5}$ L. M. Blinov, V. M. Fridkin, S. P. Palto, A. V. Sorokin, and S. G. Yudin, Thin Solid Films 284, 474 (1996).

${ }^{6}$ W. S. Yun, J. J. Urban, Q. Gu, and H. Park, Nano Lett. 2, 447 (2002).

${ }^{7}$ J. E. Spanier, A. M. Kolpak, J. J. Urban, I. Grinberg, L. Ouyang, W. S. Yun, A. M. Rappe, and H. Park, Nano Lett. 6, 735 (2006).

${ }^{8}$ Y. Luo, I. Szafraniak, N. D. Zakharov, V. Nagarajan, M. Martin Steinhart, R. B. Wehrspohn, J. H. Wendorff, R. Ramesh, and M. Alexe, Appl. Phys. Lett. 83, 440 (2003).

${ }^{9}$ W. Ma, C. Harnagea, D. Hesse, and U. Gösele, Appl. Phys. Lett. 83, 3770 (2003).

${ }^{10}$ Z. Hu, M. Tian, B. Nysten, and A. M. Jonas, Nature Mater. 8, 62 (2009).

${ }^{11}$ Y. Tajitsu, Jpn. J. Appl. Phys., Part 1345418 (1995).

${ }^{12}$ A. Konno, K. Shiga, H. Suzuki, T. Koda, and S. Ikeda, Jpn. J. Appl. Phys., Part 1 39, 5676 (2000).

${ }^{13}$ F. Xia, H. Xu, F. Fang, B. Razavi, Z.-Y. Cheng, Y. Lu, B. Xu, and Q. M. Zhang, Appl. Phys. Lett. 78, 1122 (2001).

${ }^{14}$ T. Nakajima, R. Abe, Y. Takahashi, and T. Furukawa, Jpn. J. Appl. Phys., Part 2 44, L1385 (2005).

${ }^{15}$ T. Furukawa, T. Nakajima, and Y. Takahashi, IEEE Trans. Dielectr. Electr. Insul. 13, 1120 (2006).

${ }^{16}$ X. Q. Chen, H. Yamada, T. Horiuchi, and K. Matsushige, Jpn. J. Appl. Phys., Part 1 37, 3834 (1998).

${ }^{17}$ T. Fukuma, K. Kobayashi, T. Horiuchi, P. Yamada, and K. Matsushige, Jpn. J. Appl. Phys., Part 1 39, 3830 (2000).

${ }^{18}$ A. V. Bune, V. M. Fridkin, S. Ducharme, L. M. Blinov, S. P. Palto, A. V. Sorokin, S. G. Yudin, and A. Zlatkin, Nature (London) 391, 874 (1998).

${ }^{19}$ J. Choi, C. N. Borca, P. A. Dowben, A. Bune, M. Poulsen, S. Pebley, S. Adenwalla, S. Ducharme, L. Robertson, V. M. Fridkin, S. P. Palto, N. N. Petukhova, and S. G. Yudin, Phys. Rev. B 61, 5760 (2000).

${ }^{20}$ B. J. Rodriguez, S. Jesse, S. V. Kalinin, J. Kim, and S. Ducharme, Appl. Phys. Lett. 90, 122904 (2007).

${ }^{21}$ R. Tadros-Morgane, T. Steinmetz, R. Florange, and H. Kliem, Ferroelectrics 304, 47 (2004).

${ }^{22}$ H. Kliem and R. Tadros-Morgane, J. Phys. D: Appl. Phys. 38, 1860 (2005).

${ }^{23}$ S. Ducharme, V. M. Fridkin, A. V. Bune, S. P. Palto, L. M. Blinov, N. N. Petukhova, and S. G. Yudin, Phys. Rev. Lett. 84, 175 (2000).

${ }^{24}$ G. Vizdrik, S. Ducharme, V. M. Fridkin, and S. G. Yudin, Phys. Rev. B 68, 094113 (2003).

${ }^{25}$ R. V. Gaynutdinov, O. A. Lysova, A. L. Tolstikhina, S. G. Yudin, V. M. Fridkin and S. Ducharme, Appl. Phys. Lett. 92, 172902 (2008).

${ }^{26}$ C. M. Othon, J. Kim, S. Ducharme, and V. M. Fridkin, J. Appl. Phys. 104 054109 (2008).

${ }^{27}$ M. Bai and S. Ducharme, Appl. Phys. Lett. 85, 3528 (2004).

${ }^{28}$ S. Ducharme, S. P. Palto, and V. M. Fridkin, in Ferroelectric and Dielectric Thin Films, edited by H. S. Nalwa (Academic, San Diego, 2002), Vol. 3, pp. 545-591.

${ }^{29}$ A. Gruverman, H. Tokumoto, A. S. Prakash, S. Aggarwal, B. Yang, M. Wuttig, R. Ramesh, O. Auciello, and T. Venkatesan, Appl. Phys. Lett. 71, 3492 (1997).

${ }^{30}$ A. L. Kholkin, E. L. Colla, A. K. Tagantsev, D. V. Taylor, and N. Setter, Appl. Phys. Lett. 68, 2577 (1996). 